NUREG/CR-5701

SAND91-0539

NUREG/CR--5701

TI91 015353

\title{
A Performance Assessment Methodology for High-Level Radioactive Waste Disposal in Unsaturated, Fractured Tuff
}

Manuscript Completed: June 1991

Date Published: July 1991

Prepared by

D. P. Gallegos

Sandia National Laboratories

Albuquerque, NM 87185-5800

\section{DISCLAIMER}

This report was prepared as an account of work sponsored by an agency of the United States Government. Neither the United States Government nor any agency thereof, nor any of their employees, makes any warranty, express or implied, or assumes any legal liability or responsibility for the accuracy, completeness, or usefulness of any information, apparatus, product, or process disclosed, or represents that its use would not infringe privately owned rights. Reference herein to any specific commercial product, process, or service by trade name, trademark, manufacturer, or otherwise does not necessarily constitute or imply its endorsement, recommendation, or favoring by the United States Government or any agency thereof. The views and opinions of authors expressed herein do not necessarily state or reflect those of the United States Government or any agency thereof.

Prepared for

Division of Engineering

Office of Nuclear Regulatory Research

U.S. Nuclear Regulatory Commission

Washington, DC 20555

NRC FIN A1266

\section{MASTER}




\section{DISCLAIMER}

Portions of this document may be illegible in electronic image products. Images are produced from the best available original document. 


\begin{abstract}
Sandia National Laboratories, under contract to the U.S. Nuclear Regulatory Commission, has developed a methodology for performance assessment of deep geologic disposal of high-level nuclear waste. The applicability of this performance assessment methodology has been demonstrated for disposal in bedded salt and basalt; it has since been modified for assessment of repositories in unsaturated, fractured tuff. Changes to the methodology are primarily in the form of new or modified ground water flow and radionuclide transport codes. A new computer code, DCM3D, has been developed to model three-dimensional ground-water flow in unsaturated, fractured rock using a dualcontinuum approach. The NEFTRAN II code has been developed to efficiently model radionuclide transport in time-dependent velocity fields, has the ability to use externally calculated pore velocities and saturations, and includes the effect of saturationdependent retardation factors. In order to use these codes together in performanceassessment-type analyses, code-coupler programs were developed to translate DCM3D output into NEFTRAN II input.
\end{abstract}

In addition to flow and transport codes, other portions of the performance assessment methodology were evaluated as part of modifying the methodology for tuff. The scenario methodology developed under the bedded salt program, considered adequate, was not altered, but has been applied to tuff. An investigation of the applicability of uncertainty and sensitivity analysis techniques to non-linear models indicates that Monte Carlo simulation remains the most robust technique for these analyses. No changes have been recommended for the dose and health effects models, nor the biosphere transport models. Additionally, a number of outstanding, but unresolved, technical issues have been identified. 


\section{CONTENTS}

1.0 INTRODUCTION $\ldots \ldots \ldots \ldots \ldots \ldots \ldots \ldots \ldots \ldots \ldots \ldots \ldots \ldots$

1.1 Background and Objectives .................... 1

1.2 History of the SNL Performance Assessment Methodology . . . . . . 2

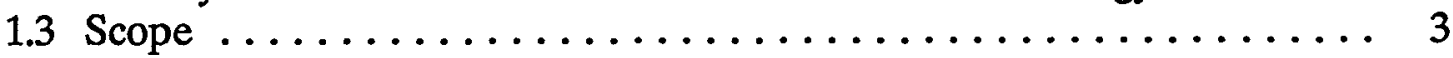

2.0 COMPONENTS OF THE PERFORMANCE ASSESSMENT

METHODOLOGY ...................... 5

2.1 System Description $\ldots \ldots \ldots \ldots \ldots \ldots \ldots \ldots \ldots \ldots \ldots \ldots$

2.2 Scenario Development and Screening $\ldots \ldots \ldots \ldots \ldots \ldots \ldots \ldots$

2.3 Consequence Analysis . . . . . . . . . . . . . . . . 9

2.3.1 Ground Water Flow Model $\ldots \ldots \ldots \ldots \ldots \ldots \ldots, 9$

2.3.2 Source-Term Model . . . ................ 13

2.3.3 Geosphere Radionuclide Transport Model .......... 14

2.3.4 Biosphere Radionuclide Transport Model ........... 18

2.3.5 Dose to Man and Health Effects Model ........... 18

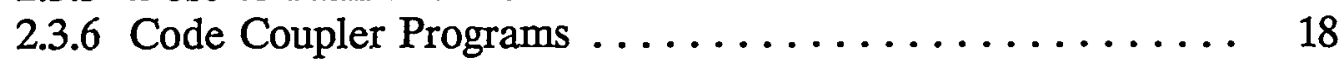

2.4 Uncertainty and Sensitivity Analyses $\ldots \ldots \ldots \ldots \ldots \ldots \ldots \ldots 20$

3.0 OUTSTANDING TECHNICAL ISSUES $\ldots \ldots \ldots \ldots \ldots \ldots \ldots \ldots \ldots$

4.0 SUMMARY $\ldots \ldots \ldots \ldots \ldots \ldots \ldots \ldots \ldots \ldots \ldots \ldots \ldots \ldots \ldots \ldots \ldots \ldots \ldots$

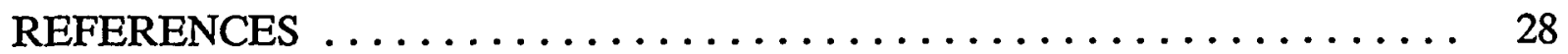




\section{PREFACE}

This report concludes the development by Sandia National Laboratories for the U.S. Nuclear Regulatory Commission (NRC) of a performance assessment methodology for the deep geologic disposal of high-level nuclear waste (HLW). This work originally began in 1976 (under FIN A1192), with the intention of developing tools and procedures that would allow the NRC to conduct an independent performance assessment of an HLW disposal site in bedded salt. This first phase was concluded with a demonstration of the use of the computer codes and probabilistic risk assessment techniques embodied in the methodology. In 1981, the NRC initiated the current program (FIN A1266) at SNL with the primary objective of modifying and extending the bedded-salt methodology to alternative geologic media such as basalt, welded tuff, granite, and domed salt. At the time, these alternative geologic formations were also being considered as possible hosts for an HLW repository in the U.S. The existing models were modified where necessary to make the methodology applicable to basalt, and the use of the resulting methodology was subsequently demonstrated. Since then, the methodology has been reexamined and the tools have been modified, or new tools developed where necessary, to render the methodology applicable to unsaturated, fractured tuff. Throughout these changes, the structure of the Sandia performance assessment methodology has remained the same. The recently modified tools, which will be described briefly in this report, have been transferred from SNL to the NRC and its contractors. 


\section{ACKNOWLEDGEMENT}

The author would like to thank C.D. Updegraff (GRAM, Inc.), N.E. Olague (SNL), and J.C. Helton (Arizona State University) for contributing to the completion of this report and the current project. Much of the discussion presented in this report is the result of work conducted by these individuals. 


\subsection{INTRODUCTION}

The U.S. Nuclear Regulatory Commission (NRC), in its role as the regulating agency for the geologic disposal of high-level nuclear waste (HLW), has contracted Sandia National Laboratories (SNL) to develop a methodology for performance assessment of nuclear waste isolation in geologic media. The SNL methodology has been developed for the NRC's Office of Nuclear Regulatory Research to use in evaluating the acceptability of potential HLW repository sites being considered by the U.S. Department of Energy (DOE). The SNL methodology is built around the six quantitative regulatory criteria for the disposal of HLW promulgated in both the Environmental Protection Agency (EPA) standard (40 CFR Part 191) [EPA, 1985] ${ }^{1}$ and the NRC rule (10 CFR Part 60) [NRC, 1986]. The EPA standard applies to the performance of the overall system, whereas the NRC rule sets forth subsystem requirements. The SNL methodology provides tools and procedures for assessing compliance with these rules and regulations.

The SNL methodology has been developed, and previously demonstrated for hypothetical HLW repository sites located in bedded salt (saturated, porous medium) [see Cranwell et al., 1987] and basalt (saturated, fractured medium) [see Bonano et al., 1989a]. Although the organization and philosophy of the current methodology are, in principle, applicable to a site located in tuff, the individual components (e.g., computer codes, data analysis techniques) require modification in order to deal with unique problems associated with the simulation of attendant processes in an unsaturated, fractured medium. This report provides a discussion of the current methodology and how it has been modified to be applied to HLW disposal in tuff.

\subsection{Background and Objectives}

The NRC, under its broad grant of authority under the Atomic Energy Act [1954], is responsible for regulating both the peaceful uses of nuclear energy and the radiological health and safety to the public. In 1982, the U.S. Congress passed legislation to provide for the permanent disposal of HLW. The Nuclear Waste Policy Act [NWPA, 1982] made the DOE responsible for the design, construction, operation, and decommissioning of a geologic repository for the disposal of spent nuclear fuel and HLW. In 1986, three sites were recommended for site characterization: Deaf Smith County, Texas (bedded salt), Hanford, Washington (basalt), and Yucca Mountain, Nevada (welded tuff). The Nuclear Waste Policy Act was later amended [NWPAA, 1987], specifying that only

${ }^{1}$ The United States Court of Appeals, $1^{\text {st }}$ Circuit, 7/17/87, vacated the EPA HLW standard 40 CFR 191 and remanded the EPA individual protection and ground water protection requirements for further consideration. While this action by the court may result in numerical criteria that differ from the EPA's original values, the content and form of the requirements are not expected to change. Therefore, the structure and philosophy of SNL performance assessment methodology has remained the same. 
Yucca Mountain would undergo site characterization.

The acceptability of any HLW disposal site and its ability to show compliance with the EPA and NRC regulations will likely be judged based on performance assessment analyses. In fact, the EPA's containment requirements [EPA, 1985] explicitly state that performance assessment will be used to evaluate the risk associated with the disposal system. As defined by the EPA [1985], a performance assessment is

an analysis that: (1) identifies the processes and events that might affect the disposal system; (2) examines the effect of these processes and events on the performance of the disposal system; and (3) estimates the cumulative releases of radionuclides, considering the associated uncertainties, caused by all significant processes and events. These estimates shall be incorporated into an overall probability distribution of cumulative release to the extent practicable.

Davis et al. [1990b] identified, generically, the components of an overall performance assessment, including phenomena that can affect the performance of the repository, the processes by which those phenomena are produced, and the parameters associated with those processes.

In general, the primary objective of the NRC program at SNL is to develop a generic, comprehensive performance assessment methodology for analysis of radioactive waste disposal in geologic media. A secondary objective of the methodology is to examine its capabilities, and thereby identify its limitations, and incorporate or recommend the necessary improvements. The SNL methodology provides support to the NRC primarily through the just mentioned objectives. However, the SNL methodology also provides procedures to assist in rule-making and licensing of potential disposal sites. Lastly, the SNL methodology implicitly provides techniques for guiding research and development needs. The objectives of the current program are to review and examine the existing methodology, modify the components of the methodology for unsaturated, fractured tuff, and transfer the technology contained in the methodology to the NRC and its contractors.

\subsection{History of the SNL Performance Assessment Methodology}

In 1976, the NRC initiated a program (FIN A1192) at SNL with the intent of developing a comprehensive methodology for performance assessment of deep geologic disposal of HLW in bedded salt formations. Under that program, the structure and procedures of the methodology were developed, and the use of the methodology was demonstrated 
[Cranwell et al., 1987]. Models for ground water flow and radionuclide transport through bedded salt (assumed to be a saturated, porous medium) were developed, in addition to models for biosphere radionuclide transport, and dosimetry and health effects. Techniques for sensitivity and uncertainty analyses were also developed under that program.

In 1981, the NRC initiated the current program (FIN A1266) at SNL with the primary objective of modifying and extending the bedded-salt methodology to alternative geologic media such as basalt, welded tuff, granite, and domed salt. At that time, these other geologic formations were also being considered as potential host formations for an HLW repository in the U.S. As mentioned earlier, the number of potential host formations was reduced to three (bedded salt, basalt, and tuff), then to one (tuff). These changes in the U.S. geologic repository program have driven the development of the methodology.

Initially, the applicability of the bedded salt methodology to other media (eg. basalt) was assessed based on the similarities between media properties. Existing models were then modified where necessary to make the methodology applicable to basalt. Models for processes and mechanisms not considered in the previous methodology were also developed and incorporated into the methodology. For the most part, modeling changes were limited to the ground water flow and radionuclide transport models. With the completion of the development work, the use of the resulting basalt methodology was demonstrated [Bonano et al., 1989a].

In 1987 , steps were initiated to modify the performance assessment methodology so that it would be applicable to HLW disposal in unsaturated, fractured media (eg., tuff). To study the properties and processes in unsaturated, fractured media, Parsons et al. [1991] investigated the ground water flow and radionuclide transport processes for a hypothetical HLW repository site in unsaturated tuff. Although a number of key processes were identified, they noted that a great deal of uncertainty in the conceptual models for such a system currently exists. The uncertainty in conceptual models notwithstanding, these findings recognized that the existing flow and transport models were inadequate for unsaturated zone analyses, and they also provided guidance as to the new models that should be developed for performance assessment analysis.

\subsection{Scope}

The products developed under the SNL performance assessment methodology have been integrated into a computational methodology to be used to quantitatively assess those aspects of the performance of an HLW repository located in unsaturated, fractured tuff which are related to ground-water movement and radionuclide transport from the 
repository to the accessible environment. At present, the SNL methodology is equipped to analyze only far-field scenarios; that is, near-field and very-near-field simulations are outside the scope of the SNL methodology. These portions of the disposal system (repository and the nearby surrounding geologic formations) were being addressed by other NRC contractors. Certain developments will be necessary to make the SNL methodology complete in the sense that appropriate processes could be analyzed at any scale. However, the general structure of the SNL methodology is amendable to incorporation of the necessary models to analyze the near field and very near field. Alternatives to the SNL methodology may exist or may be developed in the future. The general structure of the SNL performance assessment methodology could be a basis for other existing or future methodologies.

The individual components and the integrated tuff methodology have been delivered to the NRC; however, unlike the salt and basalt methodologies, the tuff methodology is not scheduled to be demonstrated by SNL staff. Rather, this report provides a description of the overall tuff methodology and the components contained therein. Because a number of the tools developed under the salt and basalt methodologies have not changed as a result of the different geologic media under consideration (eg., dose and health effects models, biosphere transport models), they will be discussed only very briefly in this report. The discussion here will concentrate on the aspects of the methodology that have been modified to treat the unique problems associated with a repository in an unsaturated, fractured medium. 


\subsection{COMPONENTS OF THE PERFORMANCE ASSESSMENT METHODOLOGY}

The SNL performance assessment methodology contains a number of specific, necessary components. These components can be grouped into four of general categories:

- methods for selecting, combining and screening events and processes (scenarios) that represent realistic future states of the disposal system and have an impact on the transport of radionuclides away from the repository,

- mathematical and numerical models for use in simulating physical and chemical processes associated with scenarios and estimating the corresponding consequences associated with those processes,

- probabilistic and statistical techniques for conducting sensitivity and uncertainty analyses, and techniques to express the risk associated with the repository system,

- procedures for using the codes and techniques embodied in the methodology.

The performance assessment methodology is shown schematically in Figure 2.1. This figure illustrates the relationships between the components and also demonstrates the iterative nature of performance assessment. The methodology is intentionally generic

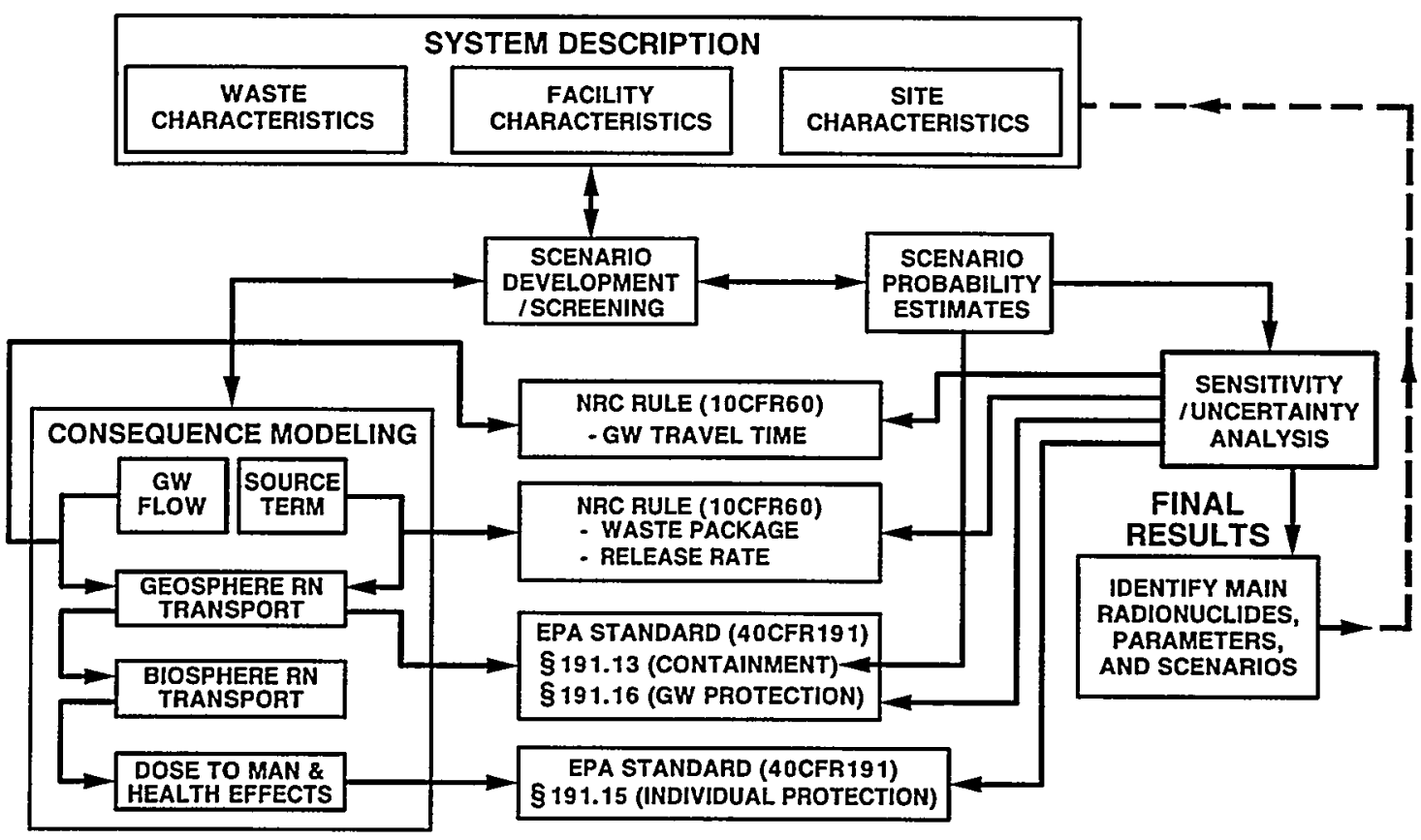

Figure 2.1. SNL Performance Assessment Methodology for HLW Disposal 
in nature, allowing it to be applicable to different geologic media. The same structure has been used for the bedded-salt methodology [Cranwell et al., 1987] and the basalt methodology [Bonano et al., 1989a], and now provides the basis for the tuff methodology.

The modular design of the methodology allows for easy modification. For example, the transition from the basalt methodology to the tuff methodology, required, for the most part, modification or replacement of only the ground water flow and radionuclide transport models. Although these models are linked to one another, they may still operate independently, and consequently can easily be changed. The structure of the methodology also allowed the models for flow and transport in the saturated zone to be retained for modeling these processes beneath the water table. The modular design also allows for evaluation of each regulation independently. For instance, only the ground water flow model need be executed to assess compliance with the NRC ground water travel time requirement, whereas the ground water flow model, a source-term model, and a radionuclide-transport model are necessary to predict integrated discharge of radionuclides to the accessible environment. This interdependency of models, indicated in the latter case, facilitates and requires consistency among the different models of the system behavior. The methodology is not merely a procedure for assessing compliance with regulations, but also provides the ability to screen scenarios based on the consequences indicated by intermediate results. Through uncertainty and sensitivity analyses, the methodology allows for the identification of key scenarios, processes, parameters, and radionuclides that would have a significant impact on the results of a performance assessment analysis.

\subsection{System Description}

The system description is a general category in the methodology which is repository and site specific, and is normally the initial step in the performance assessment analysis. It involves the description of the characteristics of the waste, the engineered facility, and the geologic site. A description of the waste generally includes the type of waste, the amount and inventory of waste, and the physical, chemical, and radioactive characteristics (including decay chains, fission products, decay modes, and half-lives) of the waste. Characteristics of the engineered facility include, among other things, the size and geometry of the repository, waste emplacement configuration, the thermal load induced by the facility, the number of waste packages, and the properties of the engineered barrier materials (e.g., backfill materials). The geologic site is described by its geologic structure, lithology, stratigraphy, mineralogy, and other physical and chemical characteristics. Hydrological, geochemical, geomechanical, and thermal properties are consequently included in this description. 


\subsection{Scenario Development and Screening}

Because of the time frames of interest, scenario definition plays an essential role in performance assessment of HLW disposal sites. A scenario is a set of naturally occurring, human-induced and/or repository-induced conditions that represent realistic future states of the disposal system such that the release and transport of radionuclides from the repository might be affected [adapted from Cranwell et al., 1990]. The SNL methodology for scenario development and screening was developed as part of the bedded-salt performance assessment methodology [Cranwell et al., 1987] and is described in greater detail elsewhere [Cranwell et al., 1990]. A brief summary is provided here.

The procedure for selecting scenarios basically identifies a list of all possible events and processes that can affect the repository system, screens those events and processes based on well-defined criteria, combines the remaining events and processes to form scenarios, and finally screens the scenarios to produce a final set of scenarios. The procedure is systematic and follows six steps:

(1) Identify potentially disruptive events and processes that might affect the performance of the repository. A comprehensive investigation is required to identify potentially disruptive events and processes to ensure that the list is complete and that no likely important events and processes are overlooked. The list should include naturallyinduced, human-induced, and repository-induced events and processes.

(2) Classify events and processes. The classification of events and processes is conducted iteratively with Step 1 to further ensure that the initial list generated is complete. The classification of events and processes is somewhat arbitrary. For example, they can be classified in terms of their origin and physical characteristics, their effect on the repository system, or any other logical category.

(3) Screen events and processes. Next, the unimportant events and processes are screened from the initial list. Cranwell et al. [1990] recommend that this be based on three criteria: physical reasonableness, probability, and consequence. The physical reasonableness criterion eliminates those events and processes whose occurrence is impossible based on the physical or chemical properties of the system. The probability criterion eliminates those events and processes whose probability of occurrence is so small that they can effectively be dismissed from further consideration. The EPA, in Appendix B of 40 CFR 191, provides numerical guidance as to those events and processes that can be dismissed. The EPA assumes that "performance assessments need not consider categories of events or processes that are estimated to have less than one chance in 10,000 of occurring over 10,000 years." That is, events or processes with an 
annual probability of less than $1 \times 10^{-8}$ can be eliminated. Basically, the physical reasonableness criterion is a subset of the probability criterion in that it eliminates events and processes with extremely low or zero probability of occurrence. At this point, the consequence criterion is used to eliminate events and processes whose impact is so insignificant that it will have no apparent effect on the behavior of the system. The consequence criterion will have added considerations when screening scenarios.

(4) Combine events and processes to form scenarios. In this step, the remaining events and processes are combined in all possible ways to form scenarios. The result is $2^{\text {n }}$ scenarios, where $n$ is the number of events and processes that remain after Step 3. For example, if two events, E1 and E2, remain, then the possible $2^{2}$ combinations are E1 occurs and E2 occurs, E1 occurs and E2 does not occur, E1 does not occur and E2 occurs, and neither E1 nor E2 occur. The last case is referred to as the base case and represents the initial conceptualization of the repository system.

(5) Screen scenarios. Scenarios are screened using the same criteria used in step 3. Those scenarios that are considered physically unreasonable are generally those that contain conflicting events and processes. For example, the events "dike intrudes repository and acts as barrier to flow" and "dike intrudes repository and acts as conduit for flow" are incompatible within a single scenario because the dike has conflicting properties. Scenarios can also be screened based on probability of occurrence. Scenarios with an annual probability of occurrence less than $10^{-8}$ can be eliminated. The consequence criterion is used to eliminate scenarios based on the impact the scenario has on release of radionuclides to the environment. The EPA states in 40 CFR 191 that events or processes that have probability of occurrence greater than $10^{-8}$ "may be omitted from the performance assessment if there is reasonable expectation that the remaining probability distribution of cumulative releases would not be significantly change by such omissions." The consequence criterion is generally not considered when screening events and processes because it usually requires more detailed analyses.

(6) Identify final set of scenarios. The final set of scenarios are identified after executing the above steps. This is the set of scenarios on which the performance assessment will be based.

The procedure just described is general; therefore, without modification, it is applicable to waste disposal in tuff. SNL applied the methodology to a potential waste disposal site in unsaturated tuff ${ }^{2}$, but the results will not be discussed here.

${ }^{2}$ Gibbons, J.F., and Guzowski, R.V., 1989. Representative Disruptive Scenarios for Use in the Development and Demonstration of a Performance Assessment Methodology for Unsaturated Tuff: U.S Nuclear Regulatory Commission, NUREG/CR-4770, Washington DC, and Sandia National Laboratories, SAND86-7170, Albuquerque, NM, Draft submitted to the U.S. Nuclear Regulatory Commission. 


\subsection{Consequence Analysis}

Consequence analysis involves developing models to describe the attendant processes at the repository site. In general, the procedure includes (1) identifying processes that are associated with scenarios, (2) developing conceptual models, based on assumptions of system characteristics and behavior, to describe those processes, (3) developing mathematical equations to describe the processes quantitatively, and (4) solving these equations (numerically or analytically) to generate consequence realizations. In the SNL performance assessment methodology, the different processes are divided into a number of coupled sub-components. These sub-components include the ground water flow models, models for describing release from the repository (source term models), geosphere radionuclide transport models, biosphere radionuclide transport models, models for predicting dose and health effects to man, and computer programs to link models to one another (code couplers). To modify the methodology for tuff, changes were made primarily to the ground water flow model, geosphere transport model, and code couplers. The remaining models tend not to be site-specific, and were therefore retained in their present state.

\subsubsection{Ground Water Flow Model}

The purpose behind the development of an independent computer code was to provide the NRC with the ability to efficiently predict ground water travel times and ground water velocities for unsaturated, fractured rock. In doing so, this code possesses the ability to predict velocity fields; pressures, and moisture contents to be used as input for the radionuclide transport code which was also being developed as part of this methodology. Such a tool would provide the NRC with an independent mechanism to evaluate compliance with the numerical requirements promulgated in 10 CFR Part 60 and 40 CFR Part 191, and to assist in assessing the validity of proposed ground water flow models. Specifically, the code has the capability to predict ground water velocities to be used in assessing compliance with the NRC's ground water travel time rule (10 CFR Part 60) and predict flow paths and velocities necessary for EPA Containment Requirement analyses (40 CFR Part 191).

The first step taken in this code development exercise was to identify important ground water flow processes at an unsaturated, fractured HLW repository site. Upon determining these processes, a rigorous study was conducted to identify, screen, and test existing computer codes [Updegraff, 1989] to determine if any codes existed which were adequate for the intended purposes of modeling these flow processes. This study provided the basis to make the decision to either select and modify an existing code, and/or develop a new, independent code. The determination was made to use existing 
codes to simulate saturated-zone flow, to use an existing code to simulate coupled heat and flow, and to develop a new code to simulate isothermal, simultaneous fracture and matrix flow. The code developed by SNL for saturated-zone flow modeling is the SWIFT II (Sandia Waste Issolation Flow and Transport) code [Reeves et al., 1986a,b,c], which was developed as part of the basalt methodology. A code developed by the $U$. S. Geological Survey [Posson et al., 1980] has been recommended for modeling regional saturated zone flow. The code recommended for modeling coupled heat and flow in unsaturated media is the TOUGH (Transport $\underline{\text { Of }}$ Underground Groundwater and $\underline{\text { Heat }}$ ) code [Pruess, 1987]. The discussion that follows will concentrate on the new code developed by SNL and will provide some reasons for the need to develop a new code.

Conceptually, ground water flow in an unsaturated, fractured rock can occur in the porous matrix, the fractures, or simultaneously in both. Exchange of water between the fracture and matrix is controlled by the pressure within each, by the physical and chemical properties of each, and by the properties of the fracture-matrix interface. The pressures within the fracture and matrix are not necessarily equal. Liquid-phase flow in the unsaturated zone is generally thought to be predominantly vertically downward; however, non-vertical flow may occur as the result of natural-system heterogeneities. Local zones of saturation can exist within the unsaturated zone (e.g., perched water tables). Large-scale features, such as faults, can also play an important role in the flow system.

The DCM3D (ual-Continuum Model 3D) computer code [Updegraff et al., 1991] was developed based on the just-mentioned considerations. Mathematically, the flow system in DCM3D is treated as a dual-continuum model. The approach is similar to that used in petroleum reservoir engineering [van Golf-Racht, 1982]. The fractures and the matrix are each assumed to behave as a continuum (with flow governed by Darcy's Law), and are coupled by a mass-exchange or transfer term. The resulting system is one of nonlinear, coupled, partial differential equations describing the pressure field. For the matrix and fracture, respectively, these equations are given as:

$$
\begin{gathered}
C_{m} \frac{\partial P_{m}}{\partial t}=\nabla \cdot\left(\frac{k_{\text {sat } m} k_{r, m}}{\mu}\left(\nabla P_{m}+\rho g \nabla z\right)\right)-\Gamma+Q_{m} \\
C_{f} \frac{\partial P_{f}}{\partial t}=\nabla \cdot\left(\frac{k_{\text {sat } f} k_{r, f}}{\mu}\left(\nabla P_{f}+\rho g \nabla z\right)\right)+\Gamma+Q_{f}
\end{gathered}
$$


where

$$
\begin{aligned}
& C=\text { specific storage coefficient } \\
& P=\text { water pressure } \\
& k_{\text {sat }}=\text { saturated intrinsic permeability } \\
& k_{r}=\text { relative permeability } \\
& Q=\text { volumetric source term } \\
& \rho=\text { water density } \\
& g=\text { gravitational coefficient } \\
& \mu=\text { dynamic water viscosity } \\
& \Gamma=\text { fracture-matrix transfer term }
\end{aligned}
$$

The subscripts $m$ and $f$ denote matrix and fracture. The specific storage coefficient, $C$, is a function of the degree of saturation, porosity, and the rock and water compressibility [see Updegraff et al., 1991].

These governing equations are numerically differentiated in space with a block centered, integrated finite difference scheme. The time-dependent partial derivative is allowed to remain continuous. This results in a system of coupled, ordinary differential equations which will be solved over time. Within each finite-difference cell volume, all fractures within the bounds of the cell are treated as a single equivalent fracture and the matrix as a single equivalent matrix coupled to that fracture. The system of differential equations is solved with a very general differential equation solver, LSODES (Livermore Solver for Ordinary Differential Equations, Sparse). LSODES is designed to solve a set of sparse, stiff ordinary differential equations [Hindmarsh, 1983]. A system is sparse if each differential equation in the set depends on only a few dependent variables. For instance, each differential equation in a one-dimensional flow problem depends on only three dependent pressure variables. These variables are the pressures at the grid block of interest and in the grid blocks adjacent to the grid block of interest. A stiff set of equations results if there are two or more very different scales of the independent variable (time) on which the dependent variable (pressure) is changing [Press et al., 1986]. In an unsaturated ground water flow equation, the hydraulic conductivity and moisture capacity in each grid block are strongly dependent on the pressure of the grid block. Thus, the hydraulic conductivities and moisture capacities between two adjoining grid blocks can be quite difference. Therefore, the time scales of the two grid blocks can then be quite different, which causes the stiffness in the equations. LSODES uses backward difference formulae to solve the set of ordinary differential equations.

The DCM3D code is able to simulate ground water flow in unsaturated, fractured media in either one, two, or three dimensions. DCM3D is capable of modeling either a singlecontinuum (matrix flow or fracture flow), or dual-continuum (simultaneous matrix and fracture flow) problem. Saturated-zone ground water flow can also be simulated. DCM3D is capable of handling spatially and temporally varying flux and pressure 
boundary conditions and source terms. Both the boundary flux and the source term for the porous matrix and/or the fracture can be prescribed by the user for each continuum. They can also depend on the mobility ratio between the two continua. The van Genuchten [van Genuchten, 1980] equations are used to describe the unsaturated zone characteristic curves of each continuum. As used in DCM3D, these equations are:

$$
S_{e}=\frac{S-S_{r}}{S_{s}-S_{r}}=\left(\frac{1}{1+\left(\alpha P_{c}\right)^{n}}\right)^{m}
$$

and

$$
k_{r}=\sqrt{S_{e}}\left(1-\left(1-S_{e}^{1 / m}\right)^{m}\right)^{2}
$$

where

$S$ is the degree of saturation;

$S_{\mathrm{e}}$ is the effective saturation;

$S_{\mathrm{r}}$ is the residual saturation;

$S_{\mathrm{s}}$ is the saturated degree of saturation (usually equals 1.0 );

$P_{\mathrm{c}}$ is the capillary pressure

$k_{\mathrm{r}}$ is the relative permeability.

$m, n$, and $\alpha$ are fitting parameters where $m$ is related to $n$ by $m=1-1 / n$. The van Genuchten equations are assumed applicable for both matrix and fracture continua.

The fracture-matrix transfer term controls the rate of exchange of water between the fracture and matrix. In DCM3D the transfer term is assumed to be a linear function of water pressure difference between the matrix and fracture continua. In simple terms, it can be represented as:

$$
\Gamma=\gamma\left(P_{m}-P_{f}\right)
$$

where $\gamma$ is called the transfer coefficient. In saturated, fractured media, $\gamma$ is generally considered to be a constant, described by [Streltsova-Adams, 1978; van Golf-Racht, 1982]:

$$
\gamma=A_{s} \frac{k_{s a t, m}}{\mu l}
$$

where $A$ is the specific fracture surface area per unit volume, and $l$ is distance between the centroids of the fracture and matrix continua. However, as indicated earlier, in unsaturated media, the permeability will be a function of the degree of saturation. As 
a result, the transfer coefficient in the unsaturated case becomes:

$$
\gamma=A_{s} \frac{k_{s a t, m} k_{r, m}}{\mu l}
$$

where $k_{\mathrm{r}, \mathrm{m}}$ is described by Equation 4 . Finally the fracture-matrix transfer term is simplified and written as:

$$
\Gamma=\frac{A k_{r, m}}{\mu}\left(P_{m}-P_{f}\right)
$$

where $A$ is a constant and is equal to $A k_{\mathrm{s}} k_{\mathrm{sat}, \mathrm{m}} / l$.

Although $A$, as just described, is based on the specific fracture surface area, saturated matrix permeability, and "distance" between the fracture and matrix, it is input as only a bulk constant into DCM3D. Therefore, $A$ can essentially be treated as a coefficient which is adjustable to accommodate for resistance to flow at the fracture-matrix interface. The resistance will be the result of some sort of physical and/or chemical characteristics of the medium. For example, Thoma, et al. ${ }^{3}$ demonstrated that fracture coatings can play an important role in inhibiting transfer of water from fractures to matrix. In any case, the use of a constant coefficient and linear pressure dependence, is still a question that needs to be addressed, especially for unsaturated media.

In general, the output from DCM3D consists of a reprint of the input data and the matrix and fracture pressures. Darcy velocities, saturations, and moisture contents are optional output. DCM3D also produces an output plot file that can be processed to provide transport paths and transport velocities for the geosphere radionuclide transport model. For more details about the DCM3D computer code see Updegraff et al. [1991].

\subsubsection{Source-Term Model}

The release of radionuclides from the repository is commonly referred to as the source term for the radionuclide geosphere transport model. The source-term model describes the onset of release and the subsequent rate and distribution of release for each radionuclide. Implicit within the source-term model are a number of submodels that describe the mechanisms for release. These include waste-package lifetime models and models for transport through the engineered barrier system. In the SNL performance assessment methodology, a number of source term models are incorporated into the

\footnotetext{
${ }^{3}$ Thoma, S.G., Gallegos, D.P., and Smith, D.M., 1991. An Investigation of the Impact of Fracture Coatings on Fracture/Matrix Flow Interactions in Unsaturated Media: Sandia National Laboratories, SAND91-0355J, Albuquerque, NM, to be published.
} 
geosphere transport model. These are discussed here briefly.

The computer code NEFTRAN II [Olague et al., 1991] contains a separate module that calculates the source term (in the form of time-dependent release rates from the engineered barrier system) for the geosphere radionuclide transport module in the code. The source model considers the initial waste inventory, the rate of water flowing through the repository, the waste fraction in contact with the water, leach properties of the waste, radionuclide solubilities, source pore area and pore volume, and decay of radionuclides. In general, the source model in NEFTRAN II contains options for describing the mechanisms for release from the waste form (i.e., leach-limited, solubility-limited, or combination) and options for describing mechanisms for release from the repository (i.e., flow-through and mixing cell). In the leach-limited models, the leach rate can be modeled as a constant leach rate or as an exponential leach rate. The solubility-limited model is applicable in cases where radionuclide solubilities are low, leach rates are high, and/or ground water flow rates through the repository are low. The mixing-cell option provides a dilution mechanism for radionuclides prior to being released into the geosphere transport path, whereas the flow-through option assumes that radionuclides are released from the repository as they dissolve and are not subsequently diluted. An attribute of the NEFTRAN II source model that its predecessor NEFTRAN [Longsine, et al., 1987] did not have is the ability to treat time-dependent ground water flow through the source.

The source model in NEFTRAN II is executed independent of the geosphere transport model; as a result, NEFTRAN II can generate source terms for other radionuclide transport codes, and conversely, in principle (although not currently implemented) NEFTRAN II could take source terms from other models and use these in transport calculations. Also, if desired, this feature allows selected decay chains to be used for only source calculations and not be transported. For more details about the source model in NEFTRAN II, see Olague et al. [1991].

\subsubsection{Geosphere Radionuclide Transport Model}

The purpose behind the development of an independent geosphere radionuclide transport model is to provide the NRC with the ability to calculate integrated release and release rates of multiple radionuclides at a specified boundary. Such a tool would provide the NRC with an independent mechanism to assess compliance with the numerical requirements in 40 CFR Part 191. Because of the modular structure of the SNL performance assessment methodology, the geosphere radionuclide transport model must be able to take information from a ground water flow model and use this information as input to the radionuclide transport calculations. 
In the radionuclide transport code development, as in the ground water flow code development, the first step was to identify the important processes associated with radionuclide transport in unsaturated, fractured rock. From this list of processes, the dominant and most important processes were selected. Next, a number of computer codes were identified that, at least to some degree, modeled these processes. From these codes, one was to be selected in its present state, or one would be selected and modified, or a new code would be developed. However, prior to choosing one of these options, some additional considerations had to be addressed. For instance, uncertainty analysis and sensitivity analysis are integral parts of performance assessment, usually requiring large numbers of simulations. Also, as it is currently written, the performance measure in EPA containment requirements ( 40 CFR Part 191) is integrated release to the accessible environment at 10,000 years. As a result, the radionuclide transport code would have to be very efficient and be able to model transport of multiple radionuclide chains. Based on all of the above considerations, the decision was made to modify the NEFTRAN [Longsine et al., 1987] code.

The processes identified as being relevant to transport of radionuclides in unsaturated, fractured media are: convection, dispersion, diffusion, sorption, radioactive decay, speciation, complexation, ion exchange, leaching, dissolution, precipitation, redox reactions, colloid formation and transport, and gas phase transport. Of these processes, convection, diffusion, dispersion, sorption, and radioactive decay were considered to be the most important. Although these are probably also the most important processes for saturated zone transport, the mechanisms by which they occur are probably quite different. Gas-phase transport was noted as potentially very important, but with much uncertainty, and for a very limited group of radionuclides. Also considered was that, as in flow, solute transport will be dominated by the fractures, matrix, or a combination of the two. The response of the system to changes in the flow field (for example, disruptive scenarios) is another important consideration.

The NEFTRAN II (NEtwork Flow and TRANsport in Time-Dependent Velocity Fields) computer code [Olague et al., 1991] was developed based on the above considerations. NEFTRAN II is basically a performance assessment code designed to conduct computationally efficient simulations of transport of multiple radionuclide chains across large distances over long periods of time. NEFTRAN $\amalg$ has retained all the capabilities of its predecessor NEFTRAN [Longsine et al., 1987], with the addition of several new ones. The new capabilities include (1) the ability to read pore-velocity and saturations from an external file, (2) the ability to treat radionuclide transport in time-dependent velocity fields, (3) the ability to treat the effect of time-dependent saturation on radionuclide retardation, and (4) the ability to model source-term releases as a function of time-dependent flow through the source. 
The NEFTRAN II computer code is capable of simulating ground water flow and radionuclide transport in steady flow systems and radionuclide transport in timedependent flow systems. In either case, the intent is to use NEFTRAN II in conjunction with an external ground water flow model that will allow simplification of the complex flow system. This is necessary because NEFTRAN II assumes that all significant flow and transport is dominated by a series of one-dimensional flow tubes or legs. In the case of a steady flow field, an external flow model (such as SWIFT II [Reeves et al., 1986 $a, b, c])$ is used to define the flow system in terms of pressures and velocities. With the use of a particle tracking routine, this flow field can be represented as a dominant flow network. Assuming that the network structure is a valid representation of the system, NEFTRAN II can then take this information, including leg properties (length, crosssectional area, hydrologic properties) and boundary conditions (pressure heads and locations), to define the same flow network internally. The result is the ability to run multiple, computationally efficient flow simulations of the system using NEFTRAN II. Radionuclide transport would be simulated simultaneously, assuming that transport takes place along a single dominant path in the network.

NEFTRAN II can also be run without using the flow network model by direct input of pore velocities into the transport model.

For time-dependent velocity fields, the transport migration path and mean pore velocities for each leg along the path are each determined from an external flow calculation and read into NEFTRAN II. For unsaturated media, saturations for each leg along the path are also required. A code such as DCM3D [Updegraff et al., 1991] would be used to describe the flow system and a particle tracking routine would again be required to define the dominant transport migration path. Significant changes in pore velocities and/or saturations along the migration path would be determined by the ground water flow code and particle tracking routine, and subsequently read by NEFTRAN II. The underlying assumption in NEFTRAN II, however, is that the migration path remains constant over time and only the magnitude of velocity and saturation change.

NEFTRAN II models convective-dispersion transport of radionuclides through a series of one-dimensional legs or stream tubes using the Distributed Velocity Method (DVM) [Campbell et al., 1981]. The primary advantage to using the DVM is that it is suited to conduct efficient transport simulations for long simulation times and over long distances. In addition to DVM, NEFTRAN II contains an option to solve the transport equation analytically if a single chain with three or fewer members is transported through single porosity legs with all the members having identical retardation factors. The DVM partitions the radionuclides within each leg into discrete packets, and determines a distribution of velocities for the packets based on the mean retarded particle velocity and a dispersivity for each leg. Mean retarded particle velocity within a leg is the mean pore 
flow velocity divided by the particle retardation factor for that leg. Included in the transport calculation is radionuclide decay and production.

Legs along the migration path can be either single-porosity matrix, single-porosity fracture, or dual-porosity fracture. Incorporated with each dual-porosity fracture leg is an immobile matrix volume, into and out of which matrix diffusion of radionuclides can be simulated. The equation governing exchange by matrix diffusion for any given cell along the path is

$$
C_{m}(t+\Delta t)=\frac{\beta \Delta t}{n_{m} R_{m}}\left[C_{f}(t)-C_{m}(t)\right]+C_{m}(t)
$$

where

$$
\begin{aligned}
& C=\text { bulk concentration of radionuclides } \\
& \beta=\text { exchange coefficient } \\
& n=\text { porosity } \\
& t=\text { time and } \\
& R=\text { retardation factor. }
\end{aligned}
$$

The subscripts $m$ and $f$ denote matrix and fracture. Matrix diffusion is potentially important because, in theory, the matrix can essentially act as a storage volume and enhance retardation of the radionuclides [Bonano et al., 1989a].

Because the spatial orientation of the transport legs in NEFTRAN II is neither specified by the user nor implied within the code, the orientation of the legs can be arbitrary. As a result, if a dominant, non-branching, migration path (or paths) can be defined in multidimensions (two or three dimensions) by a flow calculation external to NEFTRAN II, NEFTRAN II can simulate quasi multi-dimensional transport through this path.

Input to NEFTRAN II includes a series of read and write options, problem size specification, source and source flow parameters, simulation, source and time stepping parameters, network leg and junction properties, migration path properties, decay chain parameters, and element properties. Optional output from NEFTRAN II includes a reprint of input data, integrated or cumulative release $(\mathrm{Ci})$ of each radionuclide at a discharge point, total integrated release $(\mathrm{Ci})$ of all radionuclides, discharge rate $(\mathrm{Ci} / \mathrm{yr})$ at the discharge point as a function of time, and concentration $\left(\mathrm{Ci} / \mathrm{ft}^{3}\right)$ at the discharge point as a function of time.

Further discussion of the mathematical, and numerical models used in NEFTRAN II can be found in Olague et al. [1991]. 


\subsubsection{Biosphere Radionuclide Tranșport Model}

The biosphere radionuclide transport model was developed as part of the original performance assessment methodology development effort [Cranwell et al., 1987] and is made up of two submodels: an environmental transport model and a transport-to-humans model. The model was designed to take radionuclide releases estimated by the geosphere transport model and simulate the transport of these through surface water, through the food chain, and finally to humans. The biosphere radionuclide transport model is implemented in the computer code PATH1. Since it has not undergone any modifications since its original development, it will not be discussed any further here. Instead, the reader is referred to sources that will provide adequate information about the models included in PATH1 and the use of those models. These include Helton and Kaestner [1981], and Helton and Finley [1982].

\subsubsection{Dose to Man and Health Effects Model}

The dosimetry and health effects model was designed to take the results from the biosphere transport model and estimate the impact of exposure of radionuclides on humans. This model takes intake of curies and external exposure levels and converts these into potential adverse health effects. The dosimetry and health effects model is implemented in the computer code DHE. Like the biosphere radionuclide transport model, DHE has not undergone modifications since its original development, and therefore, will not be discussed any further here. Information about the model and its use can be found in Runkle et al. [1981], Runkle and Cranwell [1982], and Runkle and Finley [1983].

\subsubsection{Code Coupler Programs}

For a number of reasons, as discussed earlier, the performance assessment methodology is modular in design. This makes it convenient for evaluating particular aspects of a site such as the ground water hydrology; however, to evaluate overall system performance, the performance assessment methodology has to operate as an integrated process. Consequently, computer programs are needed to take output data and other information (such as conceptual model information) from one code and process those data into a useable form for a subsequent code in the process. These data manipulation and evaluation computer programs have been called code couplers. Specifically, for the tuff methodology, it was necessary to develop code coupler programs to provide a link between the ground water flow model (DCM3D) and the geosphere transport model (NEFTRAN II). Code coupler programs are needed to post-process the DCM3Dgenerated flow field to define a useable transport migration path for NEFTRAN II. 
This is described below.

The code-coupler, named TRACK ${ }^{4}$, is an enhanced particle-tracking routine that takes output from DCM3D (specifically, Darcy flow velocities, moisture contents and material porosities) and generates a single, nonbranching transport migration path for NEFTRAN II. As discussed earlier, characteristics of the transport migration path include the number of transport legs, the lengths of the transport legs, the mean moisture content for each transport leg, and mean pore velocity (Darcy velocity divided by moisture content) for each transport leg. If the flow simulation is based on a single-continuum, one-dimensional model, then TRACK simply calculates the pore velocities along the flow path. Because several flow-model grid blocks may eventually comprise a single transport leg, the flow velocity in each of the grid blocks is different, and each transport leg requires only one mean transport velocity, the code coupler TRACK must calculate a grid-block-weighted average velocity. Likewise, an average degree of saturation for a given leg is calculated based on the saturations in each of the grid blocks (from DCM3D) that make up that leg.

For dual-continuum flow models, the process becomes slightly more complicated. It should be recalled that NEFTRAN II can only handle transport in either a fracture or matrix continuum but not both simultaneously. As a result, for dual-continuum models TRACK evaluates the velocities in both the fracture continuum and the matrix continuum and designates one as the dominant path. TRACK simply designates the one with the higher pore velocity to be the dominant transport path. As a result, the transport path does not allow for simultaneous fracture and matrix transport, but can still treat fracture transport with matrix diffusion. The decision as to which is the dominant path is made for each grid block in the flow path. An alternative approach to transport modeling with NEFTRAN II, while using a dual continuum flow model, would be to treat the fracture and matrix continua together as an equivalent porous medium [see Erickson et al., 1986, and Dudley et al., 1988 for a discussion of equivalent porous medium concepts]. This approach was applied by Gallegos, et al. $^{5}$ in their comparison of alternative conceptual models for a single site.

TRACK defines a new transport leg whenever a change in material properties occurs along the transport path. A change in either the hydrological or the geochemical

${ }^{4}$ The code coupler TRACK is described in: Lee, C.E., 1991. TRACK: A Particle Tracking Code to Translate DCM3D Output Into NEFTRAN II Input. (Letter report transmitted from D.P. Gallegos (SNL) to T.J. McCartin (NRC), May, 1991).

${ }^{5}$ Gallegos, D.P., Pohl, P.I., and Updegraff, C.D., 1991. An Investigation of the Impact of Conceptual Model Uncertainty On Performance of a Hypothetical High-Level Nuclear Waste Repository Site in Unsaturated, Fractured Tuff: Sandia National Laboratories, SAND90-2882, Albuquerque, NM, to be published. 
properties warrants the definition of a new leg. A new leg is also defined whenever the dominant transport path changes from fracture to matrix or vice versa.

TRACK can also be applied in two-dimensional space, in which the magnitude and direction of the $\mathrm{x}$ and $\mathrm{z}$ velocity vectors for each grid block determine the particle trajectory in space. TRACK can be used with time varying velocity fields in one dimension. In this case, the assumption is made that only the magnitude of the velocity is allowed to change, and the transport migration path stays constant otherwise. Also, changes in the velocity field are assumed to occur at discrete time steps.

The output from TRACK is conveniently in the form of a NEFTRAN II input file.

\subsection{Uncertainty and Sensitivity Analyses}

Uncertainty and sensitivity analyses are conducted in accordance with the consequence analyses. Within the definition of "performance assessment" in 40 CFR Part 191, it is explicitly stated that the assessment will consider the associated uncertainties involved in estimating cumulative release of radionuclides to the accessible environment. Additionally, the EPA Containment Requirements (40 CFR 191.13) require that a reasonable expectation that compliance with $\$ 191.13$ (a) will be achieved. To achieve reasonable expectation through modeling, the models used in an analysis must adequately represent the real system and must consider and/or incorporate all sources of uncertainty, as practicably as possible. Sensitivity analysis, although not required by the regulations, is conducted to assist in focusing data collection and modeling efforts during the iterative performance assessment exercise.

Although they often use similar mathematical techniques, and are often discussed together, uncertainty and sensitivity analyses serve separate functions in performance assessment. Uncertainty analysis provides a quantitative estimate of the variation or uncertainty in model output using information about the uncertainty in the model input. Sensitivity analysis, on the other hand, refers to the quantitative estimation of the variation in the output of a model caused by the given variation in the parameters required by the model [Bonano et al., 1989a]. In other words, uncertainty analysis quantifies uncertainty in model input and output, whereas sensitivity analysis proceeds further to identify those input the uncertainty of which have the greatest influence on the uncertainty in a given output. Consequently, the two analyses complement one another. The results from the sensitivity analysis can therefore indicate those areas that, by reducing their uncertainty, will have the greatest impact on reducing uncertainty in the performance measure, and hence, increase the likelihood that reasonable expectation has been provided. 


\section{Data and Parameter Uncertainty}

Currently, the technique used in the SNL performance assessment methodology for conducting both uncertainty and sensitivity analyses is based on a Monte-Carlo-type approach. The Latin Hypercube Sampling (LHS) Technique [Iman and Shortencarrier, 1984] is used to select vectors of random samples of parameters from their respective probability distribution functions. These parameter vectors are then used in the consequence models to generate distributions of output. These distributions of output are generated for each scenario and, to assess compliance with the containment requirements in 40 CFR Part 191, the output from all scenarios are combined and represented in the form of a complementary cumulative distribution function (CCDF). Bonano and Wahi [1990] provide a comprehensive discussion of this procedure, including generation of a CCDF. Sensitivity analysis can be conducted (using a regression analysis) simultaneous to the uncertainty analysis given the distributions of input and output.

This sampling-based approach was successfully applied to the models used in the demonstration of the bedded-salt methodology [Cranwell et al., 1987] and the demonstration of the basalt methodology [Bonano et al., 1989a]. However, with the modification of the methodology for tuff, came the advent of nonlinear models for ground water flow (i.e., models based on nonlinear differential equations); whereas the models for which this approach was previously applied to were linear models (i.e., were based on linear equations). In response, SNL conducted an investigation to assess the applicability of different techniques for uncertainty and sensitivity analysis to nonlinear models, including the sampling-based approach ${ }^{6}$. Four approaches were identified and evaluated: differential analysis, Monte Carlo analysis, response-surface methodology, and Fourier amplitude sensitivity test (FAST)). The investigation states that the type of model does not, in general, provide a guide as to the uncertainty or sensitivity analysis technique that should be used; although, it was recognized that nonlinear models are more difficult to deal with, have solution spaces that are more difficult to characterize, and are more sensitive to perturbations in input than linear models. It was also recognized that regardless of the type of model (linear or nonlinear), the relationship between model input and model output tends to be nonlinear. Based on these observations, and for a number of other reasons, the recommendation made by this investigation, was that for most purposes related to performance assessment of HLW disposal, the Monte Carlo approach should be the method of choice. It should be noted, however, that no one approach will be better than all the others for all purposes. This notwithstanding, the reasons for recommending Monte Carlo, as taken from the above investigation, are summarized below.

\footnotetext{
${ }^{6}$ Helton, J.C., 1990. Applicability of Uncertainty and Sensitivity Analysis Techniques to Nonlinear Models: Letter Report for NRC FIN A1266 (transmitted in letter from D.P. Gallegos (SNL) to T.J. McCartin (NRC), September 13, 1990).
} 
First, because the Monte Carlo approach allows full stratification over the range of each independent variable, it is capable of dealing with large uncertainties in these variables. Differential analysis, which is inherently local about a base-case value for the independent variable, and response surface methodology are particularly not suited to deal with large uncertainties. As a result of the multiple-realization nature of the technique, Monte Carlo simulation also provides direct estimates of distribution functions for dependent variables. Differential analysis and FAST provide only single value estimates for the uncertainty in the dependent variables. The quality of the estimates provided by the response surface methodology are bound by the response surface approximation to the original model. Because they do not require any modifications to the original model, Monte Carlo approaches are generally straightforward to use. Differential analysis, response surface methodology and FAST, on the other hand, require a large amount of additional specialized knowledge before they can be applied. In addition, the estimates are no better than the surrogate model or design. The Monte Carlo approach is also effective for propagating uncertainty through a series of models because, as mentioned above, it provides direct estimates of dependent variable distribution functions. The other techniques, again, are not suited for this. Monte Carlo techniques create a detailed mapping from initial input to analysis results. Once produced, this mapping may be used as a basis for subsequent analyses. Finally, nonlinear models tend to be less stable in their behavior than linear models, making full stratification across the range of the independent variable particularly important. Also, because nonlinear models are generally more computationally complex than linear models, a technique that does not require modifications to the model is desirable.

Some of the drawbacks of Monte Carlo analysis should also be recognized. First, because it requires multiple model evaluations, Monte Carlo analysis, in principle, tends to be computationally expensive. Latin Hypercube Sampling [Iman and Shortencarrier, 1984] has been recommended to reduce the number of necessary evaluations. However, a drawback of the sampling approach is that LHS does not seem to directly allow for treatment of spatial variation and spatial correlation of parameters. Stochastic approaches [see Gelhar and Gutjahr, 1982; Gutjahr et al., 1985, and Bonano et al., 1987] have been proposed to deal with this aspect of uncertainty analysis. These stochastic approaches, when applied to solving the radionuclide transport problem, provide the mean and variance of the dependent variable (concentration) given the mean and variance of the ground water flow velocity and the correlation scale. This is done using only a single simulation, but more importantly accounts directly for spatial variability. Solution of the inverse ground water flow problem using geostatistics is another proposed approach [see Kitanidis and Vomoris, 1983; Hoeksema and Kitanidis, 1984, 1985]. Based on relatively few independent variable measurements, the solution of the inverse problem produces conditioned head, transmissivity, and velocity fields that can subsequently be used in ground water flow and radionuclide transport simulations. 
Bonano et al. [1989b] applied the geostatistical approach to the estimation of ground water travel times at a repository site.

Zimmerman et al. [1990], under a related NRC program (FIN A1165), provide a comprehensive review of techniques for propagating data and parameter uncertainties in HLW repository performance assessment models. Included in the report by Zimmerman et al. is also a discussion of the application of these techniques to sensitivity analysis.

\section{Uncertainty in the Future State of the System}

In addition to data and parameter uncertainty, performance assessment modeling for HLW disposal necessarily incorporates modeling uncertainty, and uncertainty associated with predicting the future state of the repository system (scenario uncertainty) [Bonano and Cranwell, 1988; Davis et al., 1990a]. Uncertainty in the future state of the system is associated mainly with three sources: developing the initial, comprehensive list of events and processes that make up scenarios, estimating the probability of occurrence for each scenario, and estimating the consequences of the scenario [Bonano and Cranwell, 1988]. The use of a systematic approach for developing and screening scenarios (such as that described by Cranwell et al. [1990]) combined with the appropriate use of formalized expert judgement [see Bonano et al., 1990] has been recommended as an effective approach to account for uncertainty in describing the future state of the system. The use of formalized expert judgement can help increase the likelihood that a complete set of events and processes will be selected, meaningful criteria for screening scenarios will be developed and applied, and all available information is used to assign probabilities to scenarios.

\section{Model Uncertainty}

Because models are, by definition, simplifications of reality, there is uncertainty inherently associated with them. Model uncertainty includes conceptual model uncertainty, mathematical model uncertainty, and uncertainties resulting from implementing the mathematical model in a computer code (e.g., coding errors, computational limitations, user errors). The importance of treating conceptual model uncertainty and the fact that quantifying and reducing this uncertainty will increase confidence in the analysis has been recognized [Bonano and Cranwell, 1988; Davis et al., 1990a; de Marsily, 1989]. As demonstrated by Gallegos et al. (see footnote 5), uncertainty in the fundamental assumptions used to develop conceptual models can have a significant impact the performance of a site. As a result of concerns such as these, international cooperative studies, such as INTRACOIN [1986], INTRAVAL [1987], and HYDROCOIN [NRC, 1988a and 1988b; Andersson et al., 1988; SKI, 1990], and from GEOVAL [Davis and Goodrich, 1990], have been conducted, implicitly recognizing the problem of model uncertainty and, in principle, provide approaches to quantifying and perhaps reducing model uncertainty (including conceptual, mathematical, and numerical 
model uncertainty). In each of these studies, the process of validation is generally recognized as the most important method for reduction of model uncertainty.

In its present form, the SNL performance assessment methodology is tailored to treating data and parameter uncertainty and uncertainty in the future state of the system; however, it is not readily capable of quantifying conceptual model uncertainty and propagating that uncertainty to the results of the performance assessment. If the uncertainty in alternative conceptual models can be quantified, then, in principle, it can be propagated, through the consequence analysis in the same way scenario uncertainty is propagated. Gallegos et al. (see footnote 5) did not quantify conceptual model uncertainty and therefore, represented alternative conceptual models for a single scenario by a series of corresponding CCDFs. However, this procedure would quickly become very complicated for an overall performance assessment because, for each scenario, a different set of plausible conceptual models can exist.

The treatment of mathematical and numerical model uncertainty, on the other hand, fall outside the quantitative aspect of performance assessment. Mathematical uncertainty, as stated above, can be dealt with through validation. Similarly, numerical model (computer code) uncertainty must be reduced through verification, benchmarking, and quality assurance. These exercises, validation, verification, benchmarking, and quality assurance, are conducted outside, but not independent, of the computational performance assessment. 


\subsection{OUTSTANDING TECHNICAL ISSUES}

Although the SNL performance assessment methodology has been modified for unsaturated, fractured media, it is by no means complete. The recent modifications were made knowing that much uncertainty in ground water flow and radionuclide transport processes in unsaturated, fractured media still exists. As a result of this and through the continuing reevaluation of the methodology, a number of outstanding technical issues have been identified for the technical community to address. The ones considered to be most important are discussed below.

The first issue is the validity of continuum approach for flow and transport modeling, particularly, in unsaturated, fractured media. The primary basis for this concern is that, in ground water flow systems, the continuum approach, typically, does not allow for "short circuits" through the system. Short circuits can be thought of as preferential flow paths or bypasses through the system. Under the continuum approach, these short circuits cannot occur because the flow processes are assumed to occur over some representative elementary volume (REV), which is essentially a macroscopic average of microscopic phenomena. The possible problem with the approach is that the microscopic properties of the medium could possibly provide mechanisms for short circuits. The magnitude of the problem escalates as the size of the REV increases. The most obvious example of a continuum model used in ground water flow modeling, and one whose validity is particularly suspect in unsaturated, fractured rock, is Darcy's Law. The validity of Darcy's Law in unsaturated, fractured rock is questionable primarily because of the system on which it was based and developed for (saturated, unconsolidated media).

The second issue is the applicability of using $\mathrm{K}_{\mathrm{d}}$ (sorption distribution coefficient) -based retardation factors in the convective-dispersion equation when modeling transport. This is an issue that is applicable to all media, saturated or unsaturated. The primary concern is that a retardation factor is a single value representation of a set of complex processes. The adequacy of this assumptions and its resultant impact on the convectivedispersion equation need to be addressed. Also, for unsaturated, media, the use of retardation factors is especially questionable because of the current techniques used to measure them. Because saturated, usually crushed, samples are used, the estimates of retardation factor are not necessarily conservative.

The third issue is the need for developing efficient numerical techniques for flow and transport modeling in unsaturated, fractured media. As discussed above, performance assessment analyses often involve numerous simulations. For complex models, and without efficient numerical techniques, these analyses can be quite expensive. Mathematical models are often simplified representations of conceptual models, partly because of the constraints placed on them by existing numerical solution techniques. In 
response, efficient numerical techniques may also assist in decreasing uncertainty in mathematical models by allowing more complex mathematical representations of coniceptual models.

The fourth issue deals with the treatment of conceptual model uncertainty in performance assessment. As pointed out earlier, the structure of the SNL performance assessment methodology is not suited to treating conceptual model uncertainty, although it is accounted for to a certain extent by treating uncertainty in data and parameters. This is not really a shortcoming of the methodology, but rather the problem lies in quantifying the uncertainty associated with conceptual models. Not treating model uncertainty can be a significant problem simply because models are the foundation for any assessment. Because of lack of data and knowledge, and the spatial and temporal scales typically considered for HLW disposal systems, it is quite possible that numerous, plausible alternative conceptual models may exist for a single site. To increase confidence that the analysis is complete, the treatment of these alternative models in a logical, systematic manner should necessarily be a part of performance assessment. As discussed in Section 2.4, the need to address model uncertainty has been recognized and efforts are being made to resolve this issue. 


\subsection{SUMMARY}

A methodology for performance assessment of an HLW repository site located in unsaturated, fractured tuff formations has been presented. The structure of the tuff methodology is identical to its predecessors, the bedded-salt methodology and basalt methodology. However, some of the tools used in the methodology have been modified to address the unique characteristics of an unsaturated, fractured medium.

Changes to the methodology are primarily in the form of new or modified ground water flow and radionuclide transport codes. A new computer code, DCM3D, has been developed to model three-dimensional ground water flow in unsaturated, fractured rock using a dual-continuum approach. The NEFTRAN II code has been developed to efficiently model radionuclide transport in time-dependent velocity fields, has the ability to use externally calculated pore velocities and saturations, and includes the effect of saturation-dependent retardation factors. So that these codes could be used together in performance-assessment-type analyses, code-coupler programs were developed to translate DCM3D output into NEFTRAN II input.

In addition to flow and transport codes, other portions of the performance assessment methodology were evaluated as part of modifying the methodology for tuff. The scenario methodology developed under the bedded salt program, considered adequate, was not altered, but has been applied to tuff. An investigation of the applicability of uncertainty and sensitivity analysis techniques to non-linear models recommends that the most robust technique for these analyses remains the Monte-Carlo-type approach. No changes have been recommended for the dose and health effects models, nor the biosphere transport models.

As part of the continuing re-evaluation of the SNL performance assessment methodology a number of outstanding, but unresolved, technical issues have been identified. These include (1) the validity of using a continuum approach, especially those based on Darcy's Law, to model ground water flow in unsaturated, fractured media, (2) the applicability of using the convective-dispersion equation with a $\mathrm{K}_{\mathrm{d}}$-based retardation factor for modeling radionuclide transport, (3) the development of efficient numerical techniques for modeling ground water flow and radionuclide transport, and (4) the treatment of conceptual model uncertainty in performance assessment. 


\section{REFERENCES}

Andersson, K., Grunfelt, B., Lindbom, B., and, Jackson, C.P., 1988. HYDROCOIN Level 2 - Final Report: Validation of Ground-Water Flow Models With Respect to Assessment of Radioactive Waste Disposal: Swedish Nuclear Power Inspectorate, Stockholm, Sweden.

Atomic Energy Act of 1954, (1954). As Amended, Public Law 83-703, 42 USC 20012259.

Bonano, E.J., and Cranwell, R.M., 1988. Treatment of Uncertainties in the Performance Assessment of Geologic High-Level Radioactive Waste Repositories: Mathematical Geology, vol. 20, no. 5, pp. 543-565.

Bonano, E.J., Davis, P.A., Shipers, L.R., Brinster, K.F., Beyeler, W.E., Updegraff, C.D., Shepherd, E.R., Tilton, L.M., and Wahi, K.K., 1989a. Demonstration of a Performance Assessment Methodology for High-Level Radioactive Waste Disposal in Basalt Formations: U.S. Nuclear Regulatory Commission, NUREG/CR-4759, Washington, DC, and Sandia National Laboratories, SAND86-2325, Albuquerque, NM.

Bonano, E.J., Davis, P.A., Bras, R.L., and Kitanidis, P.K., 1989b. Methodology for Estimating Ground-Water Travel Times At A Nuclear Waste Repository using a Geostatistical Approach: Geostatistics, vol. 2, M. Armstrong (ed.), Kluwer Academic Publishers.

Bonano, E.J., Shipers, L.R., and Gutjahr, A.L., 1987. Stochastic Analysis of Contaminant Transport in Porous Media, Analysis of a Two-Member Radionuclide Chain: Water Resources Research, vol. 23, pp. 1063-1078.

Bonano, E.J., and Wahi, K.K., 1990. Use of Performance Assessment in Assessing Compliance With the Containment Requirements in 40 CFR Part 191: U.S. Nuclear Regulatory Commission, NUREG/CR-5521, Washington, DC, and Sandia National Laboratories, SAND90-0127, Albuquerque, NM.

Campbell, J.E., Longsine, D.E., and Reeves, M., 1981. Distributed Velocity Method of Solving the Convective-Dispersion Equation: 1. Introduction, Mathematical Theory, and Numerical Implementation: Advances Water Resources, v. 4, pp. 102-108.

Cranwell, R.M., Campbell, J.E., Helton, J.C., Iman, R.L., Longsine, D.E., Ortiz, N.R., Runkel, G.E., Shortencarier, M.J., 1987. Risk Methodology for Geologic Disposal of Radioactive Waste: Final Report: U.S. Nuclear Regulatory Commission, NUREG/CR-2452, Washington, DC, and Sandia National Laboratories, SAND81-2573, Albuquerque, NM. 
Cranwell, R.M., Guzowski, R.V., Campbell, J.E., and Ortiz, N.R., 1990. Risk Methodology for Geologic Disposal of Radioactive Waste, Scenario Selection Procedure: U.S. Nuclear Regulatory Commission, NUREG/CR-1667, Washington, DC, and Sandia National Laboratories, SAND80-1429, Albuquerque, NM.

Davis, P.A., Bonano, E.J., Wahi, K.K., and Price, L.L., 1990a. Uncertainties Associated with Performance Assessment of High-Level Radioactive Waste Repositories, A Summary Report: U.S. Nuclear Regulatory Commission, NUREG/CR-5211, Washington, DC, and Sandia National Laboratories, SAND88-2703, Albuquerque, NM.

Davis, P.A., and Goodrich, M.T., 1990. A Proposed Strategy for the Validation of Ground-Water Flow and Transport Models: Proceedings of the GEOVAL 90 Symposium on Verification and Validation of Geosphere Performance Assessment Models, Swedish Nuclear Power Inspectorate, Stockholm, Sweden, May 14-17, 1990.

Davis, P.A., Price, L.L., Wahi, K.K., Goodrich, M.T., Gallegos, D.P., Bonano, E.J., and Guzowski, R.V., 1990b. Components of an Overall Performance Assessment Methodology. U.S. Nuclear Regulatory Commission, NUREG/CR-5256, Washington, DC, and Sandia National Laboratories, SAND88-3020, Albuquerque, NM.

de Marsily, G., 1989. Sources of Errors and Uncertainty in the Prediction of the Geologic Behavior of a Nuclear Waste Repository: Proceedings of the Symposium on Safety Assessment of Radioactive Waste Repositories, Organization for Economic Co-operation and Development Nuclear Energy Agency, Paris, France, October 9-13, 1989.

Dudley, A., Peters, R., Gauthier, J., Wilson, M., Tierney, M., and Klavetter, E., 1988. Total System Performance Assessment Code (TOSPAC) Volume 1: Physical and Mathematical Bases: Sandia National Laboratories, SAND85-0002, Albuquerque, NM.

EPA (Environmental Protection Agency), 1985. Environmental Standards for the Management and Disposal of Spent Nuclear Fuel, High-Level and Transuranic Radioactive Wastes: Code of Federal Regulations, Title 40, Part 191, U.S. Government Printing Office, Washington, DC.

Erickson, K.L., Chu, M.S.Y., Siegel, M.D., and Beyeler, W., 1986. Approximate Methods to Calculate Radionuclide Discharges for Performance Assessment of HLW Repositories in Fractured Rock: in Waste Management 86, Vol. 2, R.G. Post (ed.), University of Arizona, Tucson, AZ. 
Gelhar, L.W., and Gutjahr, A.L., 1982. Stochastic Solutions of the One-Dimensional Convective Dispersion Equation: Report No. H-11, Hydrology Research Program, New Mexico Institute of Mining and Technology, Socorro, NM.

Gutjahr, A.L., Bonano, E.J., and Cranwell, R.M., 1985. Treatment of Parameter Uncertainties in Modeling Contaminant Transport in Geologic Media: Stochastic Models vs. Deterministic Models with Statistical Parameter Sampling: Proc. International Symposium on the Stochastic Approach to Subsurface Flow, Paris School of Mines, Fountainebleau, France, pp.332-350.

Helton, J.C., and Kaestner, P.C., 1981. Risk Methodology for Geologic Disposal of Radioactive Waste: Model Description. and User Manual for Pathways Model: U.S. Nuclear Regulatory Commission, NUREG/CR-1636, Vol. 1, Washington, DC, and Sandia National Laboratories, SAND78-1711, Albuquerque, NM.

Helton, J.C., and Finley, N.C., 1982. PATH1 Self-Teaching Curriculum: Example Problems for Pathways-to Man Model: U.S. Nuclear Regulatory Commission, NUREG/CR-2394, Washington, DC, and Sandia National Laboratories, SAND81-2377, Albuquerque, NM.

Hindmarsh, A.C., 1983. ODEPACK, A Systemized Collection of ODE Solvers: in Scientific Computing, R.S. Stepleman et al., Eds., North-Holland, Amsterdam, pp. 55-64.

Hoeksema, R.J., and Kitanidis, P.K., 1984. An Application of the Geostatistical Approach to the Inverse Problem in Two-Dimensional Groundwater Modeling: Water Resources Research, vol. 20, pp. 1003-1020.

Hoeksema, R.J., and Kitanidis, P.K., 1985. Comparison of Gaussian Conditional Mean and Kriging Estimates in the Geostatistical Solution of the Inverse Problem: Water Resources Research, vol. 21, pp. 825-836.

Iman, R.L., and Shortencarier, M.J., 1984. A FORTRAN 77 Program and User's Guide for the Generation of Latin Hypercube and Random Samples for Use with Computer Models: U.S. Nuclear Regulatory Commission, NUREG/CR-3624, Washington, DC, and Sandia National-Laboratories, SAND83-2365, Albuquerque, NM.

INTRACOIN, 1986. International Nuclide Transport Code Intercomparison Study Final Reports Levels 2 and 3 - Model Validation and Uncertainty Analysis: Swedish Nuclear Power Inspectorate, SKI 86:2, Stockholm, Sweden.

INTRAVAL, 1987. Geosphere Transport Model Validation - A Status Report: Swedish Nuclear Power Inspectorate, SKI 87:4, Stockholm, Sweden. 
Kitanidis, R.A., and Vomoris, E.G., 1983. A Geostatistical Approach to the Inverse Problem in Groundwater Modeling (Steady State) and One-Dimensional Simulations: Water Résources Research, vol. 19, pp. 677-690.

Longsine, D.E., Bonano, E.J., and Harlan; C.P., 1987. User's Manual for the NEFTRAN Computer Code: U.S. Nuclear Regulatory Commission, NUREG/CR-4766, Washington, DC, and Sandia National Laboratories, SAND86-4766, Albuquerque, NM, 107 pp.

NRC (Nuclear Regulatory Commission), 1986. Disposal of High-Level Radioactive Wastes in Geologic Repositories: Code of Federal Regulations, Title 10, Part 60, U.S. Government Printing Office, Washington, DC.

NRC (Nuclear Regulatory Commission), 1988a. NRC Model Simulations in Support of the Hydrologic Code Intercomparison Study (HYDROCOIN), Level 1 - Code Verification: U.S. Nuclear Regulatory Commission, NUREG-1249, Volume 1, Washington, DC.

NRC (U.S. Nuclear Regulatory Commission), 1988b. NRC Model Simulations in Support of the Hydrologic Code Intercomparison Study (HYDROCOIN), Level 2 - Validation: U.S. Nuclear Regulatory Commission, NUREG-1249, Volume 2, Washington, DC.

NWPA (Nuclear Waste Policy Act), 1982. Public Law 97-425.

NWPAA (Nuclear Waste Policy Amendments Act), 1987. Public Law 100-203.

Olague, N.E, Longsine, D.E., Campbell, J.E., and Leigh, C.D., 1991. User's Manual for the NEFTRAN II Computer Code: U.S. Nuclear Regulatory Commission, NUREG/CR-5618, Washington, DC, and Sandia National Laboratories, SAND90-2089, Albuquerque, NM.

Parsons, A.M., Olague, N.E., and Gallegos, D.P., 1991. Conceptualization of a Hypothetical High-Level Nuclear Waste Repository Site in Unsaturated, Fractured Tuff: U.S. Nuclear Regulatory Commission, NUREG/CR-5495, Washington, DC, and Sandia National Laboratories, SAND89-2965, Albuquerque, NM.

Posson, D.R., Hearne, G.A., Tracy, J.V., and Frenzel, P.F., 1980. A Computer Program for Simulating Geohydrological Systems in Three Dimensions. U.S. Geological Survey, Open File Report 80-421, Washington, DC.

Press, W.H., Flannery, B.P., Teukolsky, S.A., and Flannery, W.T., 1986. Numerical Recipes, The Art of Scientific Computing: Cambridge University Press, New York. 
Pruess, K., 1987. TOUGH User's Guide. U.S. Nuclear Regulatory Commission, NUREG/CR-4645, Washington, DC, Sandia National Laboratories, SAND867104, Albuquerque, NM, and Lawrence Berkeley Laboratory, LBL-20700, Berkeley, CA.

Reeves, M., Ward, D.S., Johns, N.D., and Cranwell, R.M., 1986a. Theory and Implementation for SWIFT II, The Sandia Waste Isolation Flow and Transport Model for Fractured Media, Release 4.84. U.S. Nuclear Regulatory Commission, NUREG/CR-3328, Washington, DC, and Sandia National Laboratories, SAND83-1159, Albuquerque, NM.

Reeves, M., Ward, D.S., Johns, N.D., and Cranwell, R.M., 1986b. Data Input Guide for SWIFT II, The Sandia Waste Isolation Flow and Transport Model for Fractured Media, Release 4.84. U.S. Nuclear Regulatory Commission, NUREG/CR-3162, Washington, DC, and Sandia National Laboratories, SAND83-0242, Albuquerque, NM.

Reeves, M., Ward, D.S., Johns, N.D., and Cranwell, R.M., 1986c. SWIFT II SelfTeaching Curriculum, Illustrative Problems for the Sandia Waste Isolation Flow and Transport Model for Fractured Media. U.S. Nuclear Regulatory Commission, NUREG/CR-3925, Washington, DC, and Sandia National Laboratories, SAND84-1586, Albuquerque, NM.

Runkle, G.E., Cranwell, R.M., and Johnson, J.D., 1981. Risk Methodology for Geologic Disposal of Radioactive Waste: Dosimetry and Health Effects: U.S. Nuclear Regulatory Commission, NUREG/CR-2166, Washington, DC, and Sandia National Laboratories, SAND80-1372, Albuquerque, NM.

Runkle, G.E., and Cranwell, R.M., 1982. Risk Methodology for Geologic Disposal of Radioactive Waste: The Dosimetry and Health Effects Computer Code User's Manual: U.S. Nuclear Regulatory Commission, NUREG/CR-2346, Washington, DC, and Sandia National Laboratories, SAND81-2066, Albuquerque, NM.

Runkle, G.E., and Finley, N.C., 1983. Dosimetry and Health Effects Self-Teaching Curriculum (Illustrative Problems to Supplement the User's Manual for the Dosimetry and Health Effects Computer Code): U.S. Nuclear Regulatory Commission, NUREG/CR-2422, Washington, DC, and Sandia National Laboratories, SAND81-2488, Albuquerque, NM.

SKI (Swedish Nuclear Power Inspectorate), 1990. The International HYDROCOIN Project, Groundwater Hydrology Modelling Strategies for Performance Assessment of Nuclear Waste Disposal, Level 2: Model Validation: Nuclear Energy Agency Organisation for Economic Co-Operation and Development (OECD), Paris, FRANCE.

Streltsova-Adams, T.D., 1978. Well Hydraulics in Heterogeneous Aquifer Formations: in Advances in Hydrosciences, V.T. Chow, Ed., Academic Press, NY, pp. 357-423. 
Updegraff, C.D., 1989. Comparison of Strongly Heat-Driven Flow Codes for Unsaturated Media: U.S. Nuclear Regulatory Commission, NUREG/CR5367, Washington, DC, and Sandia National Laboratories, SAND88-7145, Albuquerque, NM.

Updegraff, C.D., Lee, C.E., and Gallegos, D.P., 1991. DCM3D, A Dual-Continuum, Three-Dimensional, Ground-Water Flow Code for Unsaturated, Fractured, Porous Media: U.S. Nuclear Regulatory Commission, NUREG/CR-5536, Washington, DC, and Sandia National Laboratories, SAND90-7015, Albuquerque, NM.

van Genuchten, M.Th., 1980. A Closed-form Equation for Predicting the Hydraulic Conductivity of Unsaturated Soils: Soil Science, vol. 44, no. 5, pp. 892-898.

van Golf-Racht, T.D., 1982. Fundamentals of Fractured Reservoir Engineering: Elsevier/North-Holland, New York.

Zimmerman, D.A., Wahi, K.K., Gutjahr, A.L., and Davis, P.A., 1990. A Review of Techniques for Propagating Data and Parameter Uncertainty in High-Level Radioactive Waste Repository Performance Assessment Models. U.S. Nuclear Regulatory Commission, NUREG/CR-5393, Washington, DC, and Sandia National Laboratories, SAND89-1432, Albuquerque, NM. 
(RESEARCH)

G. F. Birchard

MS NL/S-260

Ralph Cady

MS NL/S-260

Linda Kovach

MS NL/S-260

Tim Margulies

MS NL/S-260

T. J. McCartin MS NL/S-260

T. J. Nicholson MS NL/S-260

W. Ott

MS NL/S-260

J. D. Randall

MS NL/S-260

Mel Silberberg MS NL/S-260

(NMSS HLW)

P. Altomare

MS 4-H-3

Ronald Ballard MS 4-H-3

John Bradbury MS 4-H-3

David Brooks MS 4-H-3

Pauline Brooks MS 4-H-3
K.C. Chang

MS 4-H-3

Donald L. Chery, Jr.

MS 4-H-3

R. B. Codell

MS 4-H-3

Neil Coleman

MS 4-H-3

Seth Coplan

MS 4-H-3

Norman A. Eisenberg

MS 4-H-3

D.J. Fehringer

MS 4-H-3

William Ford

MS 4-H-3

P. S, Justus

MS 4-H-3

Keith McConnell

MS 4-H-3

Tin Mo

MS 4-H-3

M.S. Nataraja

MS 4-H-3

Jim Park

MS 4-H-3

J.J. Peshel

MS 4-H-3

J. Pohle

MS 4-H-3 
John Trapp

MS 4-H-3

Rex Wescott

MS 4-H-3

B.J. Youngblood

MS 4-H-3

A. Alonso-Santos

Universidad Politecnica de Madrid

J. Gutierrez Abascal, 2

28008 Madrid, SPAIN

George Apostolakis

University of California

5532 Boelter Hall

Los Angeles, CA 90024

D.E. Billington

Harwell Laboratory

United Kingdom Atomic Energy

Authority

Oxfordshire OX11 ORA

UNITED KINGDOM

U.S. Department of Energy (2)

Yucca Mountain Project Office

Attn: J. Boak

J.R. Dyer

P.O. Box 98518

Las Vegas, NV 89193-8518

R.L. Bras

Ralph Parsons Laboratory

Dept. of Civil Engineering

Mass. Institute of Technology

Cambridge, MA 02139

Mass. Institute of Technology (2)

Dept. of Civil Engineering

Attn: $\quad$ L.W. Gelhar, Room 48-329

D. McLaughlin, Room 48-329

Cambridge, MA 02139
P. Carboneras-Martinez

ENRESA

Calle Emilio Vargas, 7

28043 Madrid, SPAIN

Battelle Pacific Northwest Lab. (5)

Attn: C. Cole

P.G. Doctor

P. Eslinger

A.M. Liebetrau

A.E. Van Luik

3100 Port of Benton

Sigma V Building

Richland, WA 99352

J. J. K. Daemen

Department of Mining Engineering

University of Nevada

Reno, NV 89557-0139

G. de Marsily

Ecole des mines de Paris

35, Rue Saint-Honore

77305 Fontainbleau

FRANCE

P. Dickman

U.S. Department of Energy

Nevada Operations Office

P.O. Box 98518

Las Vegas, NV 89193-8518

Center for Nuclear Waste Regulatory

Analyses (7)

Southwest Research Institute

Attn: Frank Dodge

Christopher Frietas

Ronald T. Green

Prasad K. Nair

Wesley C. Patrick

John Russell

Budhi Sagar

6220 Culebra Rd.

San Antonio, TX 78228-0510 
University of Arizona (3)

Department of Hydrology and Water Resources

Attn: D.D. Evans

Todd C. Rasmussen

Shlomo P. Neuman

Tucson, AZ 85721

Katherine N. Gaither

Applied Research Technical Services, Inc.

4300 San Mateo NE, Suite A220

Albuquerque, NM 87110

D. Galson

Nuclear Energy Agency

Organization for Economic

Cooperation and Development

38, Boulevard Suchet

F-75016 Paris, FRANCE

S. Gomberg

U.S. Department of Energy

Regulatory Compliance Branch

Office of Civilian Radioactive Waste

Management

1000 Independence Avenue

Washington, DC 20585

GRAM, Inc. (7)

Attn: Michael T. Goodrich

Mark Harrington

Gretchen C. Newman

Judith A. Rollstin

C. David Updegraff

Krishan K. Wahi

Tony Zimmerman

1709 Moon St., NE

Albuquerque, NM 87112

A.L. Gutjahr

Department of Mathematics

New Mexico Institute of Mining and

Technology

Socorro, NM 87801
Sharif Heger

Department of Chemical and Nuclear

Engineering

University of New Mexico

Albuquerque, NM 87131

D.P. Hodgkinson

INTERA-ECL

Chiltern House

45 Station Road

Henley-on-Thames

Oxfordshire, RG9 1 AT

UNITED KINGDOM

Felicia Kerl

Dept. of Chemical and Nuclear Engr.

University of New Mexico

Albuquerque, NM 87131

Francis A. Kulacki

Office of the Dean

College of Engineering

Colorado State University

Fort Collins, CO 80523

Clarence E. Lee

Applied Physics, Inc.

5353 Wyoming Blvd., NE, Suite 3

Albuquerque, NM 87109

INTERA Environ. Consultants Inc. (2)

Attn: D.E. Longsine

M. Reeves

6850 Austin Center Blvd.

Suite 300

Austin, TX 78731

Sven O. Magnuson

E G \& G Idaho, Inc.

P.O. Box 1625

Idaho Falls, Idaho 83415 
A. Nies

Institut fur Tieflagerung

Theodor-Heuss-Strass 4

D-3300 Braunschweig

FEDERAL REPUBLIC OF

GERMANY

Mel G. Piepho

Westinghouse Hanford

P.O. Box 1970

Richland, WA 99352

P. Prado-Herrero

CIEMAT

Centro de Investigaciones

Energeticas Medioambientales

y Tecnologicas

Avda. Complutense, 22

28040 Madrid, SPAIN

C. Thegerstrom

Nuclear Energy Agency

Organization for Economic

Cooperation and Development

38, Boulevard Suchet

F-75016 Paris, FRANCE

B.G.J. Thompson

HM Inspectorate of Pollution

Romney House

43 Marsham Street

London SW1P 3PY

UNITED KINGDOM

Kenneth E. Torrance

Sibley School of Mechanical and

Aerospace Engineering

Upson and Grumman Halls

Cornell University

Ithaca, NY 14850

T. Vieno

Technical Research Center of Finland

P.O. Box 169

SF-00181 Helsinki 18

FINLAND
Dr. Piet Zuidema

NAGRA

Parkstrasse 23

CH-5401

Baden, SWITZERLAND

\section{SANDIA NATIONAL LABORATORIES}
3141 S. A. Landenberger (5)
3151 G. C. Claycomb (3)
3223 P. A. Davis
6300 T. O. Hunter, Actg.
6310 T. E. Blejwas, Actg.
6312 F. W. Bingham, Actg.
6312 F. C. Lauffer
6312 M. L. Wilson
6313 L. E. Shephard, Actg.
6313 M. E. Fewell
6313 J. H. Gauthier
6340 W. D. Weart
6342 D. R. Anderson
6342 M. G. Marietta
6344 E. D. Gorham
6400 D. J. McCloskey
6410 D. A. Dahlgren
6415 M. S. Tierney
6416 E. J. Bonano
6416 M. S. Y. Chu
6416 S. H. Conrad
6416 D. P. Gallegos (14)
6416 C. P. Harlan
6416 M. W. Kozak
6416 E. R. Lindgren
6416 J. T. McCord
6416 N. E. Olague
6416 P. I. Pohl
6416 L. L. Price
6416 R. R. Rao
8523 R. C. Christman 
C. Thegerstrom

Nuclear Energy Agency

Organization for Economic

Cooperation and Development

38, Boulevard Suchet

F-75016 Paris, FRANCE

B.G.J. Thompson

HM Inspectorate of Pollution

Romney House

43 Marsham Street

London SW1P 3PY

UNITED KINGDOM

Kenneth E. Torrance

Sibley School of Mechanical and

Aerospace Engineering

Upson and Grumman Halls

Cornell University

Ithaca, NY 14850

T. Vieno

Technical Research Center of Finland

P.O. Box 169

SF-00181 Helsinki 18

FINLAND

Dr. Piet Zuidema

NAGRA

Parkstrasse 23

CH-5401

Baden, SWITZERLAND
6313 J. H. Gauthier

6340 W. D. Weart

6342 D. R. Anderson

6342 M. G. Marietta

6344 E. D. Gorham

6400 D. J. McCloskey

6410 D. A. Dahlgren

6415 M. S. Tierney

6416 E. J. Bonano

6416 M. S. Y. Chu

6416 S. H. Conrad

6416 D. P. Gallegos (18)

6416 C. P. Harlan

6416 M. W. Kozak

6416 E. R. Lindgren

6416 J. T. McCord

6416 N. E. Olague

6416 P. I. Pohl

6416 L. L. Price

6416 R. R. Rao

8523 R. C. Christman

\section{SANDIA NATIONAL}

LABORATORIES

$\begin{array}{ll}3141 & \text { S. A. Landenberger (5) } \\ 3151 & \text { G. C. Claycomb (3) } \\ 3223 & \text { P. A. Davis } \\ 6300 & \text { T. O. Hunter, Actg. } \\ 6310 & \text { T. E. Blejwas, Actg. } \\ 6312 & \text { F. W. Bingham, Actg. } \\ 6312 & \text { F. C. Lauffer } \\ 6312 & \text { M. L. Wilson } \\ 6313 & \text { L. E. Shephard, Actg. } \\ 6313 & \text { M. E. Fewell }\end{array}$

